\title{
Óbitos Neonatais: uma experiência de trabalho do Comitê Regional de Vigilância ao óbito Infantil e Fetal (CRVOIF) no Departamento Regional de Saúde de Campinas (DRS-VII), no ano 2005
}

Carla de Brito Fortuna, Evelise Lima, Marlene Rizziolli Lima

Secretaria de Estado da Saúde de São Paulo. DRS-VII Campinas (SES-SP).

Endereço: Av. Orozimbo Maia, 75, Centro, CEP 13010211, Campinas, SP, Brasil.

E-mail: drs7-namor@saude.sp.gov.br

A partir de 1990, a mortalidade neonatal passou a ser o principal componente da mortalidade infantil em todo o país. Dentro desse contexto foi criado, em 2005, o CRVOIF, com a missão de investigar e avaliar os óbitos neonatais ocorridos na região, priorizando faixa etária e definindo uma metodologia de ação com a finalidade de levantar um diagnóstico situacional e desenvolver ações capazes de melhorar a qualidade da assistência materno-infantil. O Comitê analisou 10 municípios que apresentaram coeficiente de mortalidade neonatal acima de 8/10oo nascidos vivos, totalizando 59 óbitos. Destes, $68 \%$ foram classificados como inevitáveis, $22 \%$ evitáveis e $10 \%$ inconclusivos. Dos fatores de evitabilidade envolvidos nos óbitos, concluiu-se que a maioria estava relacionada à qualidade da assistência hospitalar e ao Pré-Natal. O Comitê realizou reuniões com gestores municipais/hospitais para sensibilização. 